Article

\title{
Surface Charge Properties of Marble Powder and its Effect on the Formation of Hydrates in Cement Paste
}

\author{
Xiaowei Ouyang ${ }^{1}$, Shida $\mathrm{Xu}^{1}{ }^{1}$, Liquan Wang ${ }^{1}$ and Jianzhang Huang ${ }^{2, *}$ \\ 1 Guangzhou University-Tamkang University Joint Research Center for Engineering Structure Disaster \\ Prevention and Control, Guangzhou University, Guangzhou 510006, China; xwouyang@gzhu.edu.cn (X.O.); \\ 2111816234@e.gzhu.edu.cn (S.X.); 2111716219@e.gzhu.edu.cn (L.W.) \\ 2 School of Civil Engineering, Guangzhou University, Guangzhou 510006, China \\ * Correspondence: jhuang@gzhu.edu.cn
}

Received: 7 September 2020; Accepted: 5 October 2020; Published: 9 October 2020

check for updates

\begin{abstract}
Replacing part of cement with waste stone powder can reduce the use of cement, thus reducing energy consumption and $\mathrm{CO}_{2}$ emission. Different stone powders affect the properties of cement-based materials differently. It is important to clarify the effect of the surface properties of the stone powder on the properties of cement-based materials. In this paper, the charge properties of marble powder and its effect on the formation of hydrates were investigated. Zeta potential was used to study the charge properties of the marble surface. Parallelly, the morphology of hydrates on the surface of the cement and marble particles at a very early hydration age was observed by using SEM. Finally, the influence of the surface charge properties of the marble particles on the formation of hydration products of cement was discussed. The results showed that the marble particles have specific adsorption of $\mathrm{Ca}^{2+}$ (chemical adsorption). Therefore, the marble particles in the simulated solution can adsorb a large amount of $\mathrm{Ca}^{2+}$, thus achieving a high potential value and facilitating the formation of hydrates on their surface. However, the adsorption of $\mathrm{Ca}^{2+}$ towards the surface of the cement particle is driven by a relatively weak electrostatic force. Compared with the marble particles, less $\mathrm{Ca}^{2+}$ ions are adsorbed, and thus, fewer hydrates are formed on the surface of cement particles.
\end{abstract}

Keywords: marble powder; formation; adsorption; cement paste; hydrates

\section{Introduction}

Concrete is a widely used building material. It has the advantages of low cost, a wide variety of raw materials, and can adapt to a complex environment. At present, cement is still an indispensable material in concrete; it can bond other materials together, forming a solid whole. However, the production of cement puts enormous pressure on the environment. According to statistics, the production of Portland cement causes a large amount of $\mathrm{CO}_{2}$ emission and the depletion of a great amount of non-renewable mineral resources [1,2]. At the same time, a large amount of waste stone powder is generated every year in the process of stone cutting, shaping, and polishing. Most of the stone waste powder is treated by landfills, resulting in serious environmental damage [3,4]. Replacing part of the cement with waste stone powder not only can reduce the use of cement, thus reducing energy consumption and $\mathrm{CO}_{2}$ emission, but can also reduce the environmental problems caused by the treatment of waste stone powder.

At present, there are many studies on stone powder as a substitute material of cement [5-9]. Ashish et al. [10] reported that under the effect of supplementary cementitious materials, the addition of stone powder plays a very important role in the hydration of concrete, and the addition of stone powder will not have adverse effects on the expansion and coagulation of cement paste. The research of Manpreet et al. [11] showed that after partially replacing cement with stone powder, the dry shrinkage 
of mortar was small and the strength was improved. The filling effect of stone powder makes the structure of concrete more compact and uniform, and improves the mechanical properties of concrete to a certain extent [11,12]. Vardhan et al. [13] reported that the workability of cement mortar was improved when replacing 0-50\% cement with marble powder, and the $28 \mathrm{~d}$ compressive strength of cement mortar was improved to a certain extent when the replacement rate was less than $10 \%$. Talah et al. [14] studied the influence of marble powder on the durability and mechanical properties of high performance concrete, and the amount of marble powder replacing Portland cement reached $15 \%$. It is also found that the addition of marble powder improves the compactness of the concrete structure and the durability, and reduces the permeability.

At present, most of the research on stone powder as a cement replacement is at the macro/micro-level, few studies have been carried out at the nano/micro-level. To further understand the effect of different stone powder on the properties of cement-based materials, nano/micro-level studies are needed. In this paper, the charge properties of marble powder and their effect on the formation of hydrates were investigated at the nano/micro-level. First, at the nano-level, the interaction between the surface of marble particles and the ions in cement paste was studied by measuring the zeta potential of marble particles in the simulated pore solution of cement paste. Afterward, the morphology of hydrates on the surface marble and cement particles at the very early ages of cement hydration was investigated by using SEM at the nano/micro-level. The influence of the surface charge properties of the marble particles on the formation of hydration products (mainly calcium silicate hydrate) of cement was then discussed.

\section{Materials and Methods}

\subsection{Materials}

The local ordinary Portland cement P II 42.5 (OPC) was used in this study. The marble powder used in the experiment originates from a stone processing plant. The chemical composition of the cement and marble powder was determined by X-ray fluorescence (XRF) spectrometry, as reported in Table 1. The particle size distribution of the cement and marble powder was measured using a laser light diffraction particle size analyzer (MS 2000, Malvern instruments Ltd., Malvern, UK), as given in Figure 1. XRD analysis of marble powder is shown in Figure 2.

Table 1. Chemical composition of cement and marble powder (\%).

\begin{tabular}{ccccccccc}
\hline Name & $\mathrm{SiO}_{\mathbf{2}}$ & $\mathrm{Al}_{2} \mathrm{O}_{\mathbf{3}}$ & $\mathrm{Fe}_{2} \mathrm{O}_{\mathbf{3}}$ & $\mathrm{CaO}$ & $\mathrm{MgO}$ & $\mathrm{K}_{\mathbf{2}} \mathrm{O}$ & $\mathrm{SO}_{3}$ & LOSS \\
\hline Cement & 20.07 & 5.72 & 2.78 & 63.06 & 3.17 & 0.77 & 2.74 & 2.73 \\
Marble & 2.33 & - & - & 54.21 & 0.39 & 0.16 & - & 42.59 \\
\hline
\end{tabular}

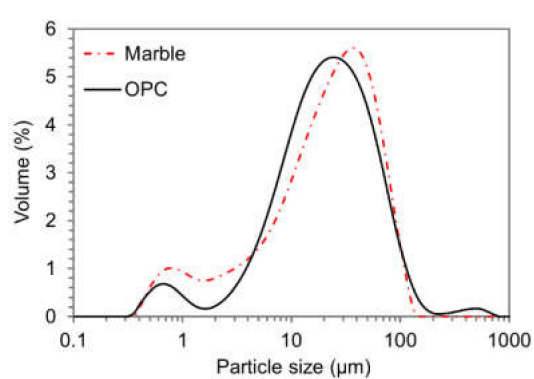

(a)

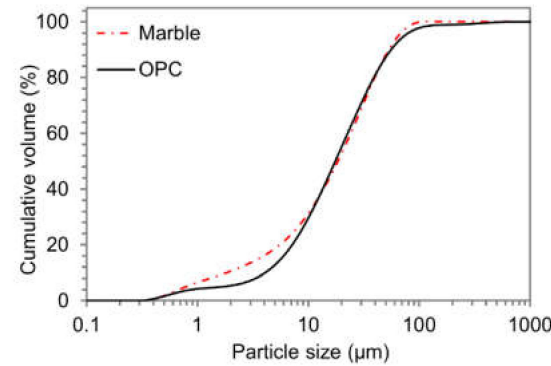

(b)

Figure 1. Particle size distribution for marble powder and cement. (a) Volume distribution; (b) cumulative volume. 


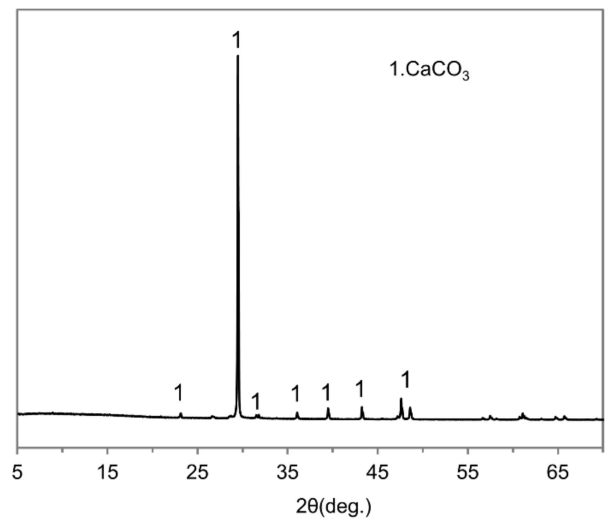

Figure 2. X-ray diffraction (XRD) pattern of marble powder.

\subsection{Zeta Potential Test}

In this experiment, the instrument used for zeta potential measurement was a Malvern Zetasizer Nano (Malvern instruments Ltd., Malvern, UK). All the particles were measured three times, and the average value of the three measurements was used as the final value. As the $\mathrm{Ca}(\mathrm{OH})_{2}$ and $\mathrm{SO}_{4}{ }^{2-}$ are the main compositions of the pore solution of cement paste, two group simulated solutions were prepared to test the zeta potential. The first group was prepared from $\mathrm{Ca}(\mathrm{OH})_{2}$ with a minimum concentration of $0.2 \mathrm{mmol} / \mathrm{L}$ and a maximum concentration of $20 \mathrm{mmol} / \mathrm{L}$. The second group is the hybrid solution $\left(\mathrm{K}_{2} \mathrm{SO}_{4}+\mathrm{Ca}(\mathrm{OH})_{2}\right)$. It is divided into two concentrations of 10 and $50 \mathrm{mmol} / \mathrm{L}$ for $\mathrm{K}_{2} \mathrm{SO}_{4}$, and the concentration of $\mathrm{Ca}(\mathrm{OH})_{2}$ ranged from 0.1 to $19.6 \mathrm{mmol} / \mathrm{L}$. The details for the solution preparation can be found in [15].

\subsection{SEM Analysis}

To observe the morphology of the hydrates on the surface of marble and cement particles at the very early ages of cement hydration, a Phenom ProX electron microscope (Phenom, FEI, Oregon, USA) was used. The acceleration voltage was $15 \mathrm{kV}$, and SED mode was applied. In the mixtures for SEM observation, $40 \%$ of cement was replaced by marble powder, and the water to binder ratio is 0.4. At a required time, approximately $1 \mathrm{~g}$ of cement paste was transferred into anhydrous alcohol to terminate hydration. The alcohol was then filtered out and the filtered powder was dried. Finally, the powder was kept in a vacuum until used. The powder particle was coated by gold before the SEM observations.

\section{Result}

\subsection{Zeta Potential}

\subsubsection{Effect of $\mathrm{Ca}^{2+}$ Concentration}

The $\mathrm{Ca}^{2+}$ ion is one of the most important factors determining the nucleation characteristics of C-S-H [16]. To study the effect of $\mathrm{Ca}^{2+}$ ions, the development of zeta potential of marble, OPC (measured by Nachbaur et al. [17]) and calcium silicate hydrate (C-S-H) particles (measured by Nachbaur et al. [17] and Helene et al. [18]) with the increase in the concentration of $\mathrm{Ca}(\mathrm{OH})_{2}$ is shown in Figure 3. As reported $[15,19,20]$ previously, the surface of both C-S-H and cement particles is negatively charged in the alkaline solution like $\mathrm{Ca}(\mathrm{OH})_{2}$. For cement particles and C-S-H particles, when the concentration of $\mathrm{Ca}(\mathrm{OH})_{2}$ ranges from 0.2 to $2 \mathrm{mmol} / \mathrm{L}$, calcium ions adsorbed on the surface of cement and $\mathrm{C}-\mathrm{S}-\mathrm{H}$ particles increase with increasing $\mathrm{Ca}(\mathrm{OH})_{2}$ concentration, partially compensating for the negative charge on the surface of the particles. It makes the absolute value of zeta potential diminish. When the concentration of calcium exceeds $2 \mathrm{mmol} / \mathrm{L}$, the adsorption of calcium ions on the 
surface of cement and C-S-H offsets the negative charge of the particles, so that the potential reverses from negative to positive.

For the marble particles, the potential was positive throughout the experiment. When the calcium concentration is $0.2 \mathrm{mmol} / \mathrm{L}$, the potential value of marble particles is $+11.47 \mathrm{mV}$. With the increase in the concentration of $\mathrm{Ca}^{2+}$, the potential value of marble particles gradually increases and reaches the maximum value of $+40 \mathrm{mV}$ when the calcium concentration is $10 \mathrm{mmol} / \mathrm{L}$. This indicates that the marble particle has a strong adsorption ability for $\mathrm{Ca}^{2+}$, leading to a very high positive potential. It can be seen that when the solution concentration is 15 and $20 \mathrm{mmol} / \mathrm{L}$, the potential of the marble particles drops abnormally. This is due to the high conductivity of the solution caused by the high $\mathrm{Ca}(\mathrm{OH})_{2}$ concentration.

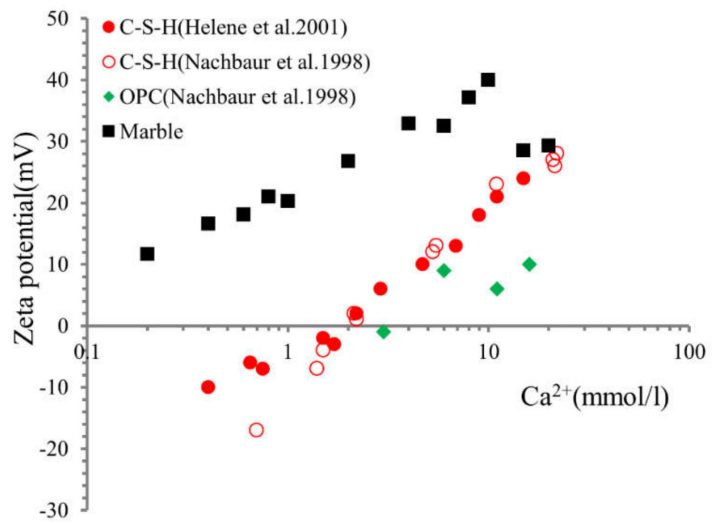

Figure 3. Development of the zeta potential of the marble, $\mathrm{C}-\mathrm{S}-\mathrm{H}$, and OPC particles with increasing $\mathrm{Ca}^{2+}$ concentration.

\subsubsection{Effect of $\mathrm{SO}_{4}{ }^{2-}$ Concentration}

Zeta potential development of the marble particle as a function of $\mathrm{Ca}^{2+}$ concentration in the $\mathrm{K}_{2} \mathrm{SO}_{4}$ solutions is shown in Figure 4. When the concentration of $\mathrm{Ca}^{2+}$ is low, the zeta potential of marble particles in $\mathrm{Ca}(\mathrm{OH})_{2}+\mathrm{K}_{2} \mathrm{SO}_{4}$ solutions is negative. Compared with the zeta potential of marble particles is $\mathrm{Ca}(\mathrm{OH})_{2}$ solution (Figure 3), it can be inferred that $\mathrm{SO}_{4}{ }^{2-}$ influences the surface adsorption of marble particles. When $\mathrm{K}_{2} \mathrm{SO}_{4}$ is $10 \mathrm{mmol} / \mathrm{L}$, zeta potential increases from -12.1 to $+5.45 \mathrm{mV}$ with the increase in $\mathrm{Ca}^{2+}$ concentration from 0.1 to $19.6 \mathrm{mmol} / \mathrm{L}$, and its iso-electric point (IEP) is located at a calcium concentration of about $3 \mathrm{mmol} / \mathrm{L}$ lower than the $\mathrm{SO}_{4}{ }^{2-}$ concentration $(10 \mathrm{mmol} / \mathrm{L})$, indicating that the adsorption of calcium ions by marble particles is stronger than $\mathrm{SO}_{4}{ }^{2-}$. When the concentration of the $\mathrm{K}_{2} \mathrm{SO}_{4}$ solution is $50 \mathrm{mmol} / \mathrm{L}$, zeta potential changes slowly with the increase of $\mathrm{Ca}^{2+}$. This is due to the fact that the high $\mathrm{SO}_{4}{ }^{2-}$ concentration lowers the chance of interactions between $\mathrm{Ca}^{2+}$ and the surface of marble particles.

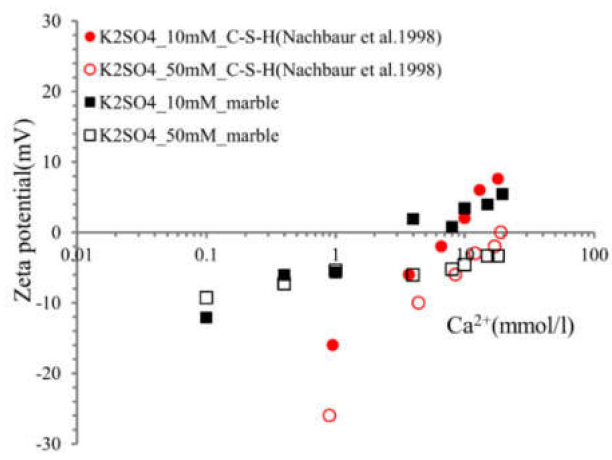

Figure 4. Development of the zeta potential of marble and $\mathrm{C}-\mathrm{S}-\mathrm{H}$ with increasing $\mathrm{Ca}^{2+}$ concentration in 10 and $50 \mathrm{mmol} / \mathrm{L} \mathrm{K}_{2} \mathrm{SO}_{4}$ solutions. 
For C-S-H particles, with the addition of $\mathrm{K}_{2} \mathrm{SO}_{4}$ into the solution, the IEP of C-S-H also appears at a higher $\mathrm{Ca}^{2+}$ concentration. When the concentration of $\mathrm{SO}_{4}{ }^{2-}$ is $10 \mathrm{mmol} / \mathrm{L}$, the iso-electric point of $\mathrm{C}-\mathrm{S}-\mathrm{H}$ is at the $\mathrm{Ca}^{2+}$ concentration of around $10 \mathrm{mmol} / \mathrm{L}$ as same as the concentration of $\mathrm{SO}_{4}{ }^{2-}$. This indicates that the adsorption of $\mathrm{Ca}^{2+}$ by $\mathrm{C}-\mathrm{S}-\mathrm{H}$ is the same as that of $\mathrm{SO}_{4}{ }^{2-}$. When the concentration of $\mathrm{SO}_{4}{ }^{2-}$ reaches $50 \mathrm{mmol} / \mathrm{L}$, zeta potential is always negative. This is because the concentration of $\mathrm{SO}_{4}{ }^{2-}$ is much higher than the concentration of $\mathrm{Ca}^{2+}$.

\subsection{SEM Observation}

Figure 5 shows the morphology of cement and marble particle. There is not much different in terms of surface morphology at the micro-level. Figure 6 shows the morphology of the surface of cement and marble particle after $15 \mathrm{~min}, 1,4$ and $7 \mathrm{~h}$ of hydration. Figure $6 \mathrm{a}, \mathrm{b}$ show the hydrates on the surface of cement and marble particles after $15 \mathrm{~min}$ of hydration, respectively. Many sparse hydration products can be seen on the surface of cement particle, among which many small nuclei may be $\mathrm{C}-\mathrm{S}-\mathrm{H}$ nano-particles, and there are also some flake hydration products, which are probably $\mathrm{CH}$ and ettringite. However, as shown in Figure $6 \mathrm{~b}$, the hydration products on the surface of marble particles are very dense after $15 \mathrm{~min}$ of hydration, and these particles are most likely the early formed C-S-H. At $1 \mathrm{~h}$, the hydrates on the cement's surface do not change much, but the hydration products become slightly larger, as shown in Figure 6c. Figure 6d shows the hydration products on the marble surface after 1 $\mathrm{h}$ hydration. Some fine nano-particles completely cover the surface. At $4 \mathrm{~h}$, it can be observed that there are many hydration products on the surface of cement particles, mainly $\mathrm{C}-\mathrm{S}-\mathrm{H}$, forming many clusters, as shown in Figure 6e. On the surface of marble particles (Figure 6f), the C-S-H grow larger. Figure $6 \mathrm{~g}$,h show the morphology of the surface of the cement and marble particles after hydration for $7 \mathrm{~h}$, respectively. On the surface of cement particles, many C-S-H particles grew relatively slenderly, and these $\mathrm{C}-\mathrm{S}-\mathrm{H}$ were randomly distributed on the surface of cement particles with various growth orientations. On the marble's surface, the elongated C-S-H grew very densely, which completely covered the surface. From these experimental results, it can be observed that the growth of hydrates on the surface of the cement and marble particles is completely different, and the surface of marble powder significantly prompts the nucleation and growth of hydration products.
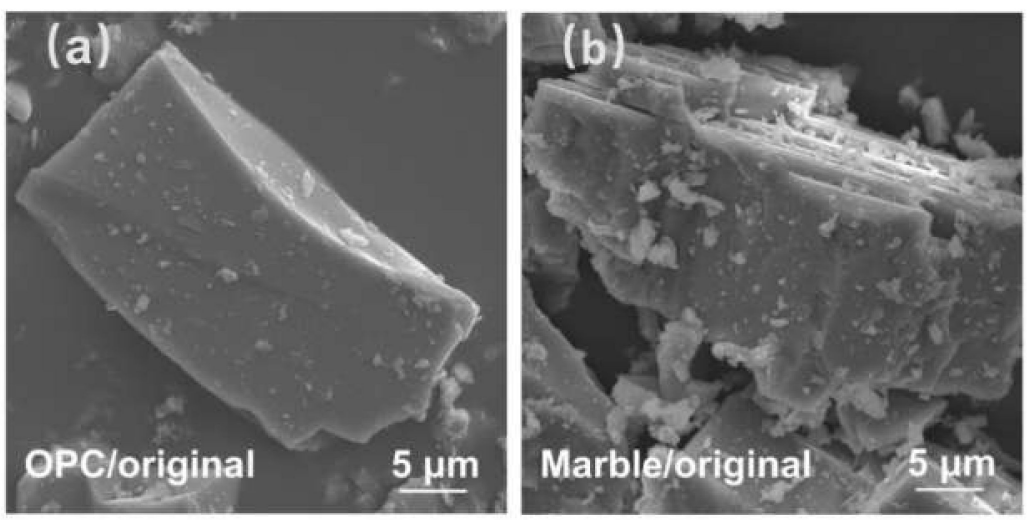

Figure 5. Morphology of OPC (a) and marble (b) particles. 

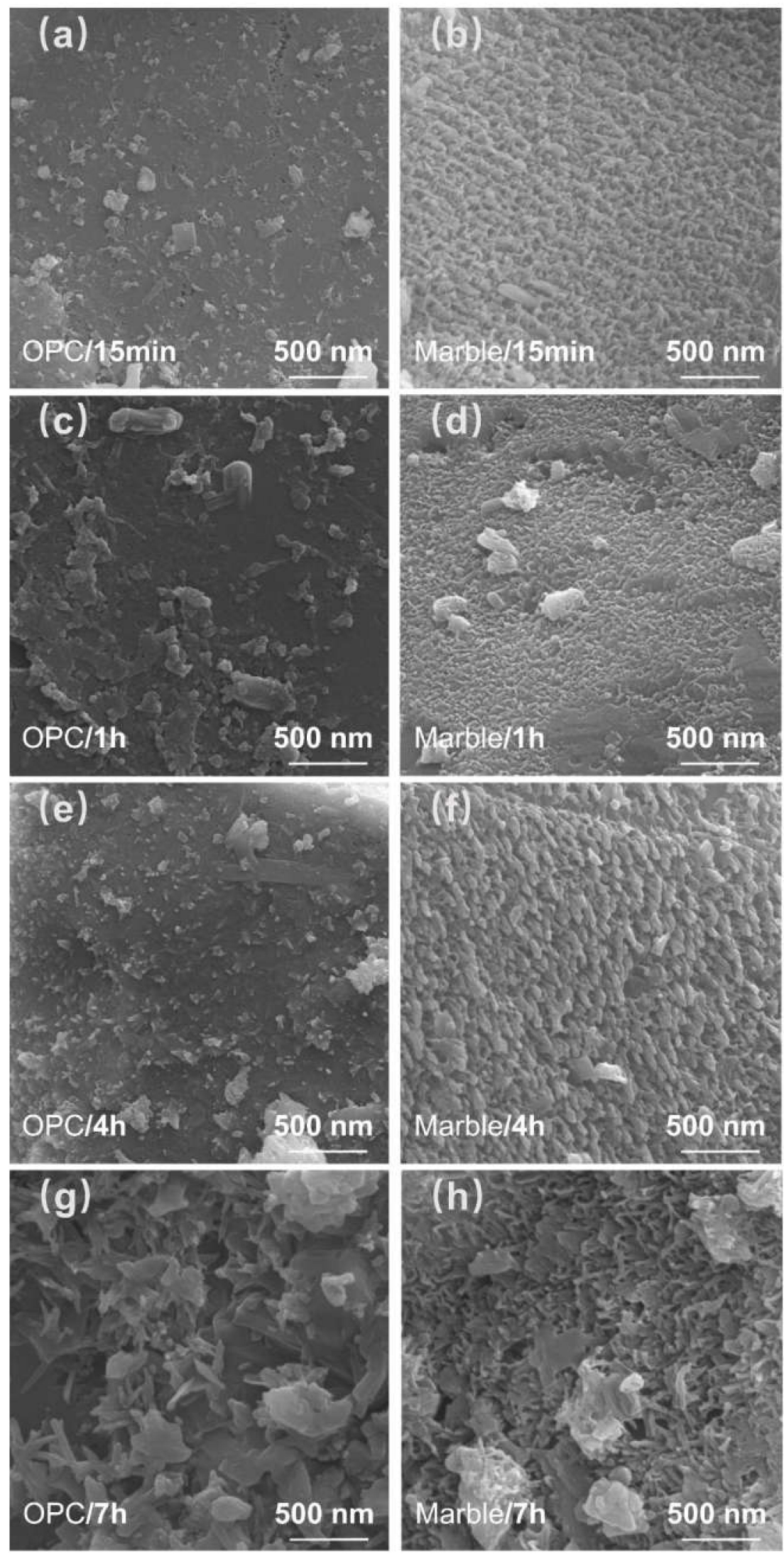

Figure 6. Morphology of hydrates on the surface of cement (OPC) particle at $15 \mathrm{~min}$ (a), $1 \mathrm{~h} \mathrm{(c),} 4 \mathrm{~h} \mathrm{(e),}$ and $7 \mathrm{~h}(\mathbf{g})$ and marble particle at $15 \mathrm{~min}(\mathbf{b}), 1 \mathrm{~h}(\mathbf{d}), 4 \mathrm{~h}(\mathbf{f})$, and $7 \mathrm{~h}(\mathbf{h})$. 


\section{Discussion}

Zeta potential refers to the charge on the shear surface of charged particles and is usually used to characterize the charge properties of a particle in solution. The zeta potential of the particles is mainly affected by ion adsorption in solution and depends on the surface chemical properties of particles [15]. There are two main types of ion adsorption at the particle interface. One is physical adsorption, mainly driven by electrostatic force and van der Waals force. The other is chemical adsorption, in which ions form chemical bonds with the surface of particles in solution or share electron pairs [1].

When cement is mixed with water, the cement particles dissolve and release ions. When the marble particles are present in the paste, these ions in the solution will be adsorbed to the surface. The results of zeta potential measurement demonstrate that the marble particles have strong adsorption of $\mathrm{Ca}^{2+}$. Studies [14,15] have shown that the adsorption between calcite surface and $\mathrm{Ca}^{2+}$ is caused by relatively strong chemical interaction, which leads to strong adsorption between calcite and $\mathrm{Ca}^{2+}$. Therefore, a large amount of $\mathrm{Ca}^{2+}$ is adsorbed on the marble's surface, leading to high zeta potential. For cement and C-S-H particles which are rich in the silicate phase, the adsorption of $\mathrm{Ca}^{2+}$ is due to electrostatic force $[15,21]$. This weak interaction force causes less $\mathrm{Ca}^{2+}$ to be adsorbed on cement and C-S-H surface, leading to relatively low zeta potential.

The nucleation and growth of C-S-H can be divided into three stages [22]. The first is the adsorption stage, in which the nucleating substrate adsorbs the relevant component ions. The second stage is the surface nucleation stage. The ions adsorbed by the nucleation substrate gradually develop from a two-dimensional nucleus to a three-dimensional nucleus. The third stage is the growth stage. As the reaction progresses, the nucleus grows gradually. Studies [23] have shown that $\mathrm{Ca}^{2+}$ is an important factor that controls the morphological of $\mathrm{C}-\mathrm{S}-\mathrm{H}$, as well as the nucleation of $\mathrm{C}-\mathrm{S}-\mathrm{H}$. Adsorption of ions in cement paste at the interface is related to $\mathrm{C}-\mathrm{S}-\mathrm{H}$ nucleation and growth.

As can be seen from the results of zeta potential measurement (Figures 3 and 4), more $\mathrm{Ca}^{2+}$ is adsorbed at the surface of the marble. As mentioned earlier, there is chemisorption between marble particles and $\mathrm{Ca}^{2+}$, which reduces the possibility of the re-diffusing of $\mathrm{Ca}^{2+}$ into the solution, thus facilitating the formation of $\mathrm{C}-\mathrm{S}-\mathrm{H}$. As a result, a large number of dense $\mathrm{C}-\mathrm{S}-\mathrm{H}$ nano-particles can be seen on the marble surface (Figure 6). Moreover, due to the tight connection between $\mathrm{Ca}^{2+}$ and the surface of marble powder particles, the growth of $\mathrm{C}-\mathrm{S}-\mathrm{H}$ has a solid foundation and tends to grow vertically. In contrast, due to the fact that the adsorption of calcium ions towards the surface of cement and C-S-H particles is driven by a weak electrostatic force, the adsorption of $\mathrm{Ca}^{2+}$ is not tight, and very easy re-diffuses back to the solution, leading to less $\mathrm{Ca}^{2+}$ adsorbed at the surface of cement particles. Consequently, very few hydrates can be observed on the cement's surface (Figure 6).

\section{Conclusions}

The purpose of this paper is to study the effect of the surface properties of stone powder on the formation of hydration products. The marble powder was used in this study. The surface charge properties of marble properties and their effect on the adsorption of $\mathrm{Ca}^{2+}$ were studied using a zeta potential test. The formation of hydrates (mainly, C-S-H) on their surfaces was observed using SEM. Finally, the influence of the surface charge properties of marble particles on nucleation and growth of hydration products was then discussed. The following conclusions can be drawn from this study: (1) The marble particles have specific adsorption of $\mathrm{Ca}^{2+}$ (chemical adsorption). The marble particles in the simulated solution can adsorb a large amount of $\mathrm{Ca}^{2+}$, thus achieving a high potential value and facilitating the formation of hydrates on its surface. (2) The adsorption of $\mathrm{Ca}^{2+}$ towards to the surface of the cement particle is driven by a relative electrostatic force. Compared with the marble particles, less $\mathrm{Ca}^{2+}$ ions are adsorbed, and thus, fewer hydrates are formed on the surface of cement particles.

Author Contributions: Methodology, X.O.; formal analysis and investigation, S.X. and L.W.; data curation and writing-original draft preparation, S.X.; writing-review and editing, supervision, and funding acquisition, X.O. and J.H. All authors have read and agreed to the published version of the manuscript. 
Funding: This research was funded by the Natural Science Foundation of Guangdong Province (Grant No. 2019A1515110799, 2020A1515010915), the National Nature Science Foundation of China (Grant No. 52008119), the Foundation for Innovative Young Talents Project of Guangdong Education Bureau (Grant No. 2018KQNCX198), and the Guangzhou Municipal Science and Technology Project (Grant No. 201904010290).

Conflicts of Interest: The authors declare no conflict of interest.

\section{References}

1. Mehta, K.P. Reducing the Environmental Impact of Concrete. Concr. Int. 2001, 10, 18-22.

2. Meyer, C. The greening of the concrete industry. Cem. Concr. Compos. 2009, 31, 601-605. [CrossRef]

3. Kuersat Esat, A.; Ince, R. A preliminary concrete mix design for SCC with marble powders. Constr. Build. Mater. 2009, 23, 1201-1210.

4. Ulubeyli, G.C.; Artir, R. Sustainability for Blast Furnace Slag: Use of Some Construction Wastes. Procedia Soc. Behav. Sci. 2015, 195, 2191-2198. [CrossRef]

5. Aliabdo, A.A.; Elmoaty, A.E.M.A.; Auda, E.M. Re-use of waste marble dust in the production of cement and concrete. Constr. Build. Mater. 2014, 50, 28-41. [CrossRef]

6. Corinaldesi, V.; Moriconi, G.; Naik, T.R. Characterization of marble powder for its use in mortar and concrete. Constr. Build. Mater. 2010, 24, 113-117. [CrossRef]

7. Gesoglu, M.; Gueneyisi, E.; Kocabag, E.M.; Bayram, V.; Mermerdas, K. Fresh and hardened characteristics of self compacting concretes made with combined use of marble powder, limestone filler, and fly ash. Constr. Build. Mater. 2012, 37, 160-170. [CrossRef]

8. Khodabakhshian, A.; Ghalehnovi, M.; De Brito, J.; Shamsabadi, E.A. Durability performance of structural concrete containing silica fume and marble industry waste powder. J. Clean. Prod. 2018, 170, 42-60. [CrossRef]

9. Silva, D.; Gameiro, F.; Brito, J.D. Mechanical Properties of Structural Concrete Containing Fine Aggregates from Waste Generated by the Marble Quarrying Industry. J. Mater. Civ. Eng. 2014, 26, 04014008. [CrossRef]

10. Ashish, D.K. Concrete made with waste marble powder and supplementary cementitious material for sustainable development. J. Clean. Prod. 2019, 211, 716-729. [CrossRef]

11. Singh, M.; Srivastava, A.; Bhunia, D. An investigation on effect of partial replacement of cement by waste marble slurry. Constr. Build. Mater. 2017, 134, 471-488. [CrossRef]

12. Rai, B.; Naushad, K.; Kr, A.; Rushad, T. Influence of Marble powder/granules in Concrete mix. Int. J. Comput. Civ. Struct. Eng. 2012, 1, 827-834.

13. Vardhan, K.; Goyal, S.; Siddique, R.; Singh, M. Mechanical properties and microstructural analysis of cement mortar incorporating marble powder as partial replacement of cement. Constr. Build. Mater. 2015, 96, 615-621. [CrossRef]

14. Huang, Y.C.; Fowkes, F.M.; Lloyd, T.B.; Sanders, N.D. Adsorption of calcium ions from calcium chloride solutions onto calcium carbonate particles. Langmuir 1991, 7, 1742-1748. [CrossRef]

15. Ouyang, X.; Koleva, D.A.; Ye, G.; Breugel, K.V. Insights into the mechanisms of nucleation and growth of C-S-H on fillers. Mater. Struct. 2017, 50, 213. [CrossRef]

16. Nehdi, M.; Mindess, S.; Aïtcin, P.-C. Optimization of high strength limestone filler cement mortars. Cem. Concr. Res. 1996, 26, 883-893. [CrossRef]

17. Nachbaur, L.; Nkinamubanzi, P.C.; Nonat, A.; Mutin, J.C. Electrokinetic Properties which Control the Coagulation of Silicate Cement Suspensions during Early Age Hydration. J. Colloid Interface Sci. 1998, 202, 261-268. [CrossRef]

18. Viallis-Terrisse, H.; Nonat, A.; Petit, J.-C. Zeta-Potential Study of Calcium Silicate Hydrates Interacting with Alkaline Cations. J. Colloid Interface Sci. 2001, 244, 58-65. [CrossRef]

19. Ouyang, X.; Koleva, D.A.; Ye, G.; van Breugel, K. Understanding the adhesion mechanisms between CSH and fillers. Cem. Concr. Res. 2017, 100, 275-283. [CrossRef]

20. Ouyang, X.; Wang, L.; Xu, S.; Ma, Y.; Ye, G. Surface characterization of carbonated recycled concrete fines and its effect on the rheology, hydration and strength development of cement paste. Cem. Concr. Compos. 2020, 114, 103809. [CrossRef] 
21. Wang, L.; Liu, Z.; Xu, S.; Ouyang, X.; Ouyang, D.; Jiao, C.; Zhang, Y. A study on the effect of ceramic polishing powder on the nucleation and growth of hydrates in cement paste. Crystals 2019, 9, 545. [CrossRef]

22. Stumm, W. The Chemistry of the Solid-Water Interface; John Wiley \& Son Inc.: Hoboken, NJ, USA, 1992.

23. Garrault-Gauffinet, S.; Nonat, A. Experimental investigation of calcium silicate hydrate (C-S-H) nucleation. J. Cryst. Growth 1999, 200, 565-574. [CrossRef]

Publisher's note: MDPI stays neutral with regard to jurisdictional claims in published maps and institutional affiliations.

(C) 2020 by the authors. Licensee MDPI, Basel, Switzerland. This article is an open access article distributed under the terms and conditions of the Creative Commons Attribution (CC BY) license (http://creativecommons.org/licenses/by/4.0/). 